\title{
Prevalence of anemia before and after initiation of antiretroviral therapy among HIV infected patients at Black Lion Specialized Hospital, Addis Ababa, Ethiopia: a cross sectional study
}

Gashaw Garedew Woldeamanuel ${ }^{1 *}$ and Diresibachew Haile Wondimu ${ }^{2}$

\begin{abstract}
Background: Anemia is the most common hematological abnormality in Human immunodeficiency virus (HIV) positive patients and a significant predictor of its progression to AIDS or death. This study was aimed to assess the prevalence of anemia before and after initiation of antiretroviral therapy (ART) among HIV positive patients attending Black Lion Specialized Hospital, Addis Ababa, Ethiopia.

Methods: A cross sectional study was conducted from January to April, 2017 in Black Lion Specialized Hospital, Addis Ababa, Ethiopia. A total of 255 patients on ART were selected using simple random sampling techniques. Sociodemographic and clinical characteristics of the study subjects were collected using structured questionnaire. Measurements of complete blood cell counts and CD4 + T cell counts were made using Sysmex XT 2000i hematology analyzer and BD FACS Count CD4 analyzer, respectively. Statistical analysis of the data (Chi-square, paired T-test, logistic regression) was done using SPSS version 20. A p-value $<0.05$ was considered as significant.

Results: Prevalence of anemia before and after ART initiation was 41.9 and $11.4 \%$ respectively. There are a significance differences in CD4 + T cell count, RBC count, hemoglobin values and RBC indices in HIV patients before and after ART initiation ( $p$-value $<0.05$ ). WHO clinical stages and CD4+ T cell counts were found to be associated with the prevalence of anemia before ART initiation. Among the total number of anemic cases, normocytic normochromic anemia was present in $71 \%$ of the cases before ART and in $58.6 \%$ of the cases after ART. The prevalence of macrocytic normochromic anemia before and after ART initiation was 4.7 and $27.6 \%$ respectively.

Conclusions: It is evident from this study that there is a remarkable reduction in the prevalence of anemia after ART initiation. However, a significant proportion of HIV patients remained anemic after 6 months of ART initiation suggesting the need for routine screening and proper treatment of anemia to mitigate its adverse effects.
\end{abstract}

Keywords: HIV, ART, Anemia, Ethiopia

\footnotetext{
* Correspondence: gashawgaredew05@gmail.com

'Department of Medicine, College of Medicine and Health Sciences, Wolkite

University, P.O. Box 07, Wolkite, Ethiopia

Full list of author information is available at the end of the article
} 


\section{Background}

Hematologic abnormalities are among the most common manifestations of advanced human immunodeficiency virus (HIV) infection and acquired immunodeficiency syndrome (AIDS) [1]. Low blood cell counts, are the most common of these disorders [2]. The frequency and severity of these hematological manifestations increased with the decline in CD4 counts [3] with anemia being the most common hematologic abnormality in HIV patients and is associated with disease progression and decreased survival [4]. However, the prevalence of anemia in HIV patients varies considerably, ranging from 1.3 to $95 \%$. Several factors including stage of HIV, age, sex and the definition of anemia used are said to account for the variations in HIV prevalence [5].

Anemia is multifactorial. HIV infection itself causes anemia, probably as a consequence of HIV infection of stromal cells. Other common causes of anemia in AIDS are anemia of chronic disease, bone marrow suppression by ART, and hemolytic anemia induced by oxidant drugs $[6,7]$. Cytokines such as interleukin 1, tumor necrosis factor and the interferon play a role in impairing erythropoietin response by reducing concentration of marrow progenitors and erythroid colonies. As ART generally diminishes these cytokines, anemia is less common than in the pre ART era. But commonly used myelosuppressive drugs in the HIV setting may contribute to anemia and even in the era of ART, anemia continues to contribute to morbidity and diminished quality of life [8].

Overall, the treatment of HIV infection with ART reduces the incidence of anemia and increases hemoglobin levels over time [9]. However, zidovudine (AZT) has also been clearly demonstrated to cause anemia [10]. Marrow erythroid hypoplasia, aplasia, and megaloblastic maturation have developed as a result of AZT therapy [8]. The effect of AZT is modest when taken as ART than administered as a single dose [11].

Different studies were conducted to assess the prevalence of anemia in HIV infected individuals. But there are only few published reports in Ethiopia on the assessment of anemia among HIV positive patients. Therefore, this study gave information about the prevalence of anemia before and after initiation of antiretroviral therapy among HIV patients who attended at ART clinic of Black Lion Specialized Hospital, Addis Ababa, Ethiopia.

\section{Methods}

\section{Study setting and study population}

Cross sectional study design was conducted at ART clinic of Black Lion Specialized Hospital, Addis Ababa, Ethiopia. This hospital is selected based on the availability of patients from all parts of the country as it is referral and specialized teaching hospital in Ethiopia. This study was conducted from January to April, 2017. During the study period, $2675 \mathrm{HIV}$ infected adults were on ART. Among those on ART, a total of 255 HIV infected patients taking ART for at least 6 months were selected randomly and included in this study. Sample size was estimated using a single population proportion formula, taking $p=20.9 \%$ (expected prevalence rate of anemia) [11], 5\% level of precision (d) with 95\% confidence interval. The inclusion criteria for this study includes; HIV positive adults greater than 18 years old at the time of ART initiation, those who were on ART for at least 6 months, patients having complete hematological values at the baseline and those who were volunteered to participate in the study. Patients transferred from other health institutions, those who were on medication, pregnant, diagnosed as having hematological diseases and other medical conditions by medical experts were excluded from the study.

\section{Data collection}

The data was collected using a structured questionnaire by five nurses working in the ART clinic. The collected information includes socio-demographics, clinical characteristics, and immunohematological profile of patients at baseline and after 6 months of ART initiation. Data on socio-demographic, clinical characteristics and baseline information of the study participants were collected by interview and review of medical records. Anthropometric measurements were carried out according to the WHO recommendations. Then, the study participants were sent to the laboratory for determination of blood cell counts. Hemoglobin concentration, RBC count and RBC indices were determined using Sysmex XT 2000i hematology analyzer whereas CD4+ T cells were assayed using the BD FACS Count system. The instruments and the procedures used for analysis of blood cell counts were the same during the two time points.

To ensure good quality data, training of data collectors, pre-testing of data collection instrument and continuous supervision of the data collection process were carried out.

\section{Definition of outcome variable and statistical analysis}

The data were cleaned, edited, checked for completeness and entered into SPSS version 20 for analysis. Anemia was defined as $\mathrm{Hgb}$ concentration less than $13 \mathrm{~g} / \mathrm{dl}$ for adult males and less than $12 \mathrm{~g} / \mathrm{dl}$ for adult females. It was further classified into mild (11-11.9 g/dl for women and $11-12.9 \mathrm{~g} / \mathrm{dl}$ for men), moderate $(8-10.9 \mathrm{~g} / \mathrm{dl})$ and severe $(<8 \mathrm{~g} / \mathrm{dl})$ for both sexes [12]. Microcytosis was defined as $\mathrm{MCV}<80 \mathrm{fl}$, macrocytosis as $\mathrm{MCV}>$ $100 \mathrm{fl}$ and hypochromia was defined as $\mathrm{MCHC}$ value $<31 \mathrm{~g} / \mathrm{dl}$ [13]. 
Descriptive statistics was used to get a clear picture of dependent and independent variables. After checking the normality of the data, paired T-test was used and also chi square was computed to determine association between dependent and independent variables. Multivariable logistic regression analysis was performed to obtain the adjusted effect of different risk factors on the odds of being anemic at baseline and after 6 months of ART initiation. A $p$-value $<0.05$ was considered as statistically significant.

\section{Results}

\section{General characteristics of study participants}

A total of 255 HIV positive patients, of which 148 (58\%) women and 107 (42\%) men were involved in this study. The overall mean age was $40.6 \pm 9.4$ years, within the range of 20-70 years old. The majority of patients were within 40-49 years of age. About 95 (37.3\%) participants were under WHO clinical stage III and the most widely used ART regimen (62.7\%) in this study was 1e (TDF3 TC-EFV). At the time of study, $61.6 \%$ of them were taking cotrimoxazole prophylaxis therapy (Table 1).

\section{Red blood cell parameters and $\mathrm{CD}^{+} \mathrm{T}$ cell counts of HIV positive patients before and after initiation of ART}

There were statistically significant differences in the mean values of $\mathrm{RBC}$ count $\left(4.41 \pm 0.71 \times 10^{6} / \mu \mathrm{l}\right.$ vs. 4.28 $\left.\pm 0.59 \times 10^{6} / \mu \mathrm{l}\right)$, hemoglobin $(12.8 \pm 1.99 \mathrm{~g} / \mathrm{dl}$ vs. $14.34 \pm$ $1.89 \mathrm{~g} / \mathrm{dl}), \mathrm{MCV}(86.34 \pm 6.42 \mathrm{fl}$ vs. $96.33 \pm 8.80 \mathrm{fl})$, $\mathrm{MCH}(29.1 \pm 2.69$ pg vs. $32.78 \pm 4.09 \mathrm{pg}), \mathrm{MCHC}(33.52$ $\pm 1.75 \mathrm{~g} / \mathrm{dl}$ vs $34.18 \pm 1.86 \mathrm{~g} / \mathrm{dl})$, RDW $(14.91 \pm 2.66 \%$ vs. $13.66 \pm 1.58 \%)$ and CD4+ T cell counts (162.5 \pm 108.6 cells $/ \mu \mathrm{l}$ vs. $347 \pm 183.17$ cells $/ \mu \mathrm{l})$ before and after ART initiation respectively. Patients after ART initiation have high hemoglobin level, $\mathrm{MCV}, \mathrm{MCH}, \mathrm{MCHC}$ and CD4+ T cell counts when compared to ART naïve patients $(p<0.001)$ (Table 2$)$.

\section{Prevalence of anemia among HIV positive patients before} and after initiation of ART

The prevalence of anemia in HIV patients was $41.9 \%$ (107/255) before ART initiation and 11.4\% (29/255) after ART initiation. About 90 (84.1\%) had mild anemia and 17 (15.9\%) had moderate anemia before ART initiation.

From anemic patients after ART initiation, about 22 (75.9\%) had mild anemia and 7 (24.1\%) had moderate anemia. Severe anemia was not found in this study. The prevalence of anemia after ART initiation was significantly decreased by $30.5 \%$.

Risk factors of anemia in HIV infected patients before and after ART initiation

From anemic patients before ART initiation, about $43.9 \%$ (47/107) were males and 40.5\% (60/148) were
Table 1 Sociodemographic and clinical characteristics of HIV positive patients taking ART at Black Lion Specialized Hospital, Addis Ababa, Ethiopia, 2017

\begin{tabular}{|c|c|c|}
\hline Variables & $\begin{array}{l}\text { Frequency } \\
(n=255)\end{array}$ & Percentage (\%) \\
\hline \multicolumn{3}{|l|}{ Age (in years) } \\
\hline $20-29$ & 33 & 12.9 \\
\hline $30-39$ & 86 & 33.7 \\
\hline $40-49$ & 96 & 37.6 \\
\hline $50-59$ & 30 & 11.8 \\
\hline $60-69$ & 9 & 3.5 \\
\hline $70-79$ & 1 & 4 \\
\hline \multicolumn{3}{|l|}{ Sex } \\
\hline Male & 107 & 42 \\
\hline Female & 148 & 58 \\
\hline \multicolumn{3}{|l|}{ Marital Status } \\
\hline Single & 67 & 26.3 \\
\hline Divorced & 43 & 16.9 \\
\hline Married & 106 & 41.5 \\
\hline Widowed & 39 & 15.3 \\
\hline \multicolumn{3}{|l|}{ Educational status } \\
\hline illiterate & 27 & 10.6 \\
\hline Primary school & 101 & 39.6 \\
\hline High school & 91 & 35.7 \\
\hline Certificate and above & 36 & 14.1 \\
\hline \multicolumn{3}{|l|}{ Employment status } \\
\hline Employed in public organization & 26 & 10.2 \\
\hline Employed in private organization & 23 & 9 \\
\hline Self employed & 57 & 22.4 \\
\hline Unemployed & 149 & 58.4 \\
\hline \multicolumn{3}{|l|}{ WHO clinical stages at baseline } \\
\hline Stage I & 41 & 16.1 \\
\hline Stage \| & 56 & 22 \\
\hline Stage III & 95 & 37.3 \\
\hline Stage IV & 63 & 24.6 \\
\hline \multicolumn{3}{|l|}{ Types of ART regimens } \\
\hline $1 c$ & 40 & 15.7 \\
\hline $1 d$ & 30 & 11.8 \\
\hline $1 e$ & 160 & 62.7 \\
\hline 1f & 25 & 9.8 \\
\hline \multicolumn{3}{|l|}{ Cotrimoxazole prophylaxis } \\
\hline Yes & 157 & 61.6 \\
\hline No & 98 & 38.4 \\
\hline
\end{tabular}

females. Similarly $42.5 \%$ (48/113) of patients were within the age of 30 to 40 years and $49.4 \%$ of patients with CD4 cell count $<200$ cells $/ \mu$ l developed anemia. There were 
Table 2 Red blood cell parameters and CD4 ${ }^{+} T$ cell counts of HIV positive adult patients at baseline and after 6 months of ART at Black Lion Specialized Hospital, Addis Ababa, Ethiopia, 2017

\begin{tabular}{llll}
\hline Parameters & $\begin{array}{l}\text { Before initiation of ART }(n=255) \\
\text { Mean } \pm \text { SD }\end{array}$ & $\begin{array}{l}\text { After } 6 \text { months of ART initiation }(n=255) \\
\text { Mean } \pm \text { SD }\end{array}$ & 0.009 \\
\hline RBC $\left(\times 10^{6} / \mu l\right)$ & $4.41 \pm 0.71$ & $4.28 \pm 0.59$ & $<0.001$ \\
Hgb $(\mathrm{g} / \mathrm{dl})$ & $12.8 \pm 1.99$ & $14.34 \pm 1.89$ & $<0.001$ \\
MCV $(\mathrm{fl})$ & $86.34 \pm 6.42$ & $96.33 \pm 8.80$ & $<0.001$ \\
MCH $(\mathrm{pg})$ & $29.1 \pm 2.69$ & $32.78 \pm 4.09$ & $<0.001$ \\
MCHC $(\mathrm{g} / \mathrm{dl})$ & $33.52 \pm 1.75$ & $34.18 \pm 1.86$ & $<0.001$ \\
RDW $(\%)$ & $14.91 \pm 2.66$ & $13.66 \pm 1.58$ & $<0.001$ \\
CD4 $(\mathrm{Cells} / \mu \mathrm{l})$ & $162.5 \pm 108.6$ & $347 \pm 183.17$ & \\
\hline
\end{tabular}

significant associations between anemia with CD4 cell count and WHO clinical stage before ART initiation. HIV patients with CD4 cell count $<200$ cells/ $\mu$ l before ART initiation had higher prevalence of anemia (49.4\%, $p<0.001)$. Similarly about $48.4 \%(p<0.05)$ patients with WHO clinical stage III/IV had anemia before ART initiation. However, there was no significant association of anemia with sex and age (Table 3).

Multiple logistic regression analysis was performed to obtain the adjusted effect of different risk factors on the odds of being anemic before initiation of ART. Table 3 summarizes the result of the final regression model. The variables; age, sex, WHO clinical stages and CD4 counts were included in the analysis. After adjusting for these factors in a multiple logistic regression analysis; clinical stage III/IV and CD4 count $<200$ cells $/ \mathrm{mm}^{3}$ were significantly associated with increased odds of being anemic.

From anemic patients after ART initiation, about 9.3\% $(10 / 107)$ were males and $12.8 \%(19 / 148)$ were females. Similarly $21.2 \%$ of patients with the age of $<30$ years and $16.2 \%$ of patients with CD4 cell count $<200$ cells $/ \mu \mathrm{l}$ developed anemia. Although, HIV patients with CD4 cell count $<200$ cells $/ \mu \mathrm{l}$ had higher prevalence of anemia (16.2\%) after ART initiation, there was no significant association between anemia and CD4 cell counts $(p=0.27)$. Similarly sex, age and ART regimen types had no significant association with anemia after ART initiation (Table 4). In multivariable logistic regression analysis, increased risk of anemia after 6 months of ART was observed among participants with age less than 30 years and CD4 count < 200 cells $/ \mathrm{mm}^{3}$ whereas the odds of being anemic was lower among individuals with TDF based ART regimen, BMI $18.5-24.9 \mathrm{~kg} / \mathrm{m}^{2}$ and male participants.

\section{Types of anemia among HIV positive patients before and after ART initiation}

From the total anemic HIV infected patients at the baseline, $71 \%$ had normocytic-normochromic anemia followed by microcytic-normochromic anemia 14.9\%. After 6 months of ART initiation, normocytic-normochromic anemia was present in $58.6 \%$ of the cases followed by macrocyticnormochromic anemia in $27.6 \%$ of the cases (Fig. 1).

Table 3 Anemia and its associated factors before ART initiation in HIV positive patients attending Black Lion Specialized Hospital, Addis Ababa, Ethiopia, 2017

\begin{tabular}{|c|c|c|c|c|c|}
\hline Variables & Anemic & Non anemic & $x^{2}$ & $P$ value & AOR $(95 \% \mathrm{Cl})$ \\
\hline \multicolumn{6}{|l|}{ Age(in years) } \\
\hline$<30$ & 13 (39.4\%) & $20(60.6 \%)$ & 0.10 & 0.95 & $1.13(0.49-2.63)$ \\
\hline $30-40$ & $48(42.5 \%)$ & $65(57.5 \%)$ & & & $1.02(0.58-1.78)$ \\
\hline$>40$ & $46(42.2 \%)$ & $63(57.8 \%)$ & & & 1.00 \\
\hline \multicolumn{6}{|l|}{ Sex } \\
\hline Male & 47 (43.9\%) & $60(56.1 \%)$ & 0.21 & 0.65 & $1.09(0.64-1.86)$ \\
\hline Female & $60(40.5 \%)$ & $88(59.5 \%)$ & & & 1.00 \\
\hline \multicolumn{6}{|c|}{ WHO clinical stages } \\
\hline Stage $|/| \mid$ & $32(32 \%)$ & $68(68 \%)$ & 6.70 & 0.01 & 1.00 \\
\hline Stage III/IV & 75 (48.4\%) & $80(51.6 \%)$ & & & $1.83(1.06-3.15)$ \\
\hline \multicolumn{6}{|c|}{ CD4 count (cells/mm³) } \\
\hline$<200$ & 89 (49.4\%) & $91(50.6 \%)$ & 14.07 & $<0.001$ & $2.91(1.57-5.39)$ \\
\hline$\geq 200$ & 18 (24\%) & $57(76 \%)$ & & & 1.00 \\
\hline
\end{tabular}

Numerical data in bold indicates the level of significance $(p<0.05), A O R$ Adjusted odds ratio, $C l$ Confidence interval, $1.00=$ reference group 
Table 4 Anemia and its associated factors after ART initiation in HIV positive patients attending Black Lion Specialized Hospital, Addis Ababa, Ethiopia, 2017

\begin{tabular}{|c|c|c|c|c|c|}
\hline Variables & Anemia & Non anemic & $x^{2}$ & $P$ value & AOR $(95 \% \mathrm{Cl})$ \\
\hline \multicolumn{6}{|l|}{ Age(in years) } \\
\hline$<30$ & $7(21.2 \%)$ & $26(78.8 \%)$ & 6.23 & 0.05 & $4.01(1.24-13.02)$ \\
\hline $30-40$ & $15(13.3 \%)$ & $98(86.7 \%)$ & & & $2.25(0.84-5.98)$ \\
\hline$>40$ & $7(6.4 \%)$ & $102(93.6 \%)$ & & & 1.00 \\
\hline \multicolumn{6}{|l|}{ Sex } \\
\hline Male & $10(9.3 \%)$ & $97(90.7 \%)$ & 1.19 & 0.28 & $0.79(0.34-1.85)$ \\
\hline Female & $19(12.8 \%)$ & 129 (87.2\%) & & & 1.00 \\
\hline \multicolumn{6}{|l|}{ ART regimen } \\
\hline TDF based & $21(11.4 \%)$ & $164(88.6 \%)$ & 0.000 & 0.99 & $0.99(0.40-2.46)$ \\
\hline AZT based & $8(11.4 \%)$ & $62(88.6 \%)$ & & & 1.00 \\
\hline \multicolumn{6}{|l|}{ Cotrimoxazole } \\
\hline NO & $9(8.9 \%)$ & $92(91.1)$ & 1.01 & 0.32 & $0.74(0.29-1.86)$ \\
\hline Yes & $20(13 \%)$ & $134(87)$ & & & 1.00 \\
\hline \multicolumn{6}{|c|}{ CD4 count (cells $/ \mathrm{mm}^{3}$ ) } \\
\hline$<200$ & $10(16.2 \%)$ & $52(83.9 \%)$ & 2.62 & 0.27 & $2.04(0.70-5.96)$ \\
\hline 200-349 & $10(12.2 \%)$ & $72(87.8 \%)$ & & & $1.44(0.52-3.99)$ \\
\hline$\geq 350$ & $9(8.1 \%)$ & $102(91.9 \%)$ & & & 1.00 \\
\hline \multicolumn{6}{|l|}{$\mathrm{BMI}\left(\mathrm{Kg} / \mathrm{m}^{2}\right)$} \\
\hline$<18.5$ & $4(12.9 \%)$ & $27(87.1 \%)$ & 0.08 & 0.96 & $0.81(0.21-3.17$ \\
\hline $18.5-24.9$ & $18(11.2 \%)$ & $143(88.8 \%)$ & & & $0.76(0.29-2.01)$ \\
\hline$\geq 25$ & 7 (11.1\%) & 56 (88.9\%) & & & 1.00 \\
\hline
\end{tabular}

$A O R$ Adjusted odds ratio, BMI Body mass index, $C /$ Confidence interval, $1.00=$ reference group

\section{Discussion}

Anemia is the most common hematological abnormality and it has been associated with an increased HIV disease progression among HIV infected patients [13]. As recovery from anemia led to improvements in patient survival, screening for anemia among HIV infected patients should be performed to decrease the risk of death and to enhance the individual's functional status [4]. All subjects in this study were under first line of antiretroviral therapy.

The present study revealed that the prevalence of anemia at the baseline was $41.9 \%$ with $84.1 \%$ mild and $15.9 \%$ moderate anemia. After 6 months of ART, the prevalence of anemia was reduced to $11.4 \%$. This finding is in agreement with a study done in Addis Ababa, Ethiopia reported that the prevalence of anemia at the

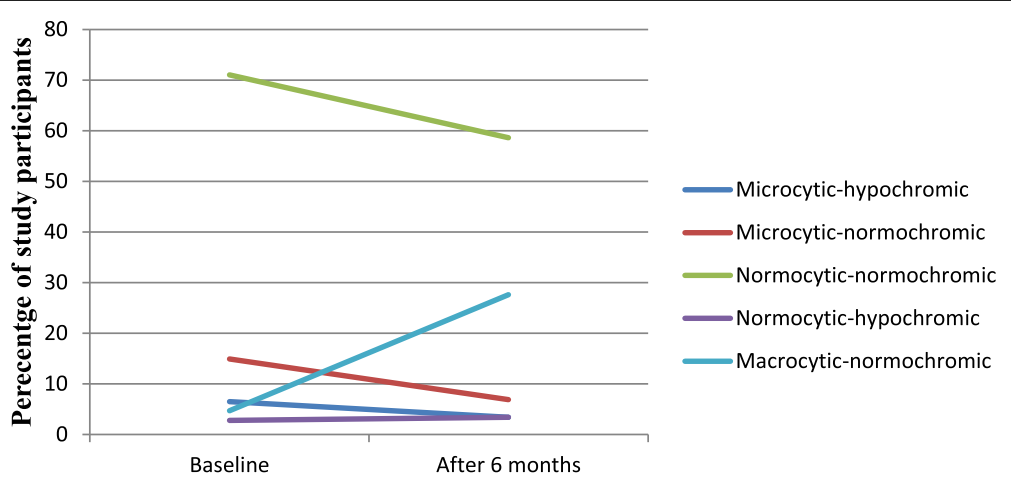

Time of assessment

Fig. 1 Types of anemia among HIV positive patients attending Black Lion Specialized Hospital, Addis Ababa, Ethiopia, 2017 
baseline was $42.9 \%$ with $79,15.6$ and $5.3 \%$ mild, moderate and severe anemia respectively. The study also added that at 12 months of ART initiation the prevalence of anemia was reduced to $14.3 \%$ [11]. In a separate study at Arba Minch, Ethiopia the prevalence of anemia at baseline was $52.3 \%$ with $28.1,22.9$ and $1.3 \%$ mild, moderate and severe anemia respectively [4]. Other studies also found different prevalence rates of anemia. A study from Hawassa, Ethiopia reported the prevalence of anemia as $23.4 \%$ before ART and $12.0 \%$ after ART [14]. A study from Jimma, Ethiopia reported the prevalence as $29.9 \%$ before ART and $16.2 \%$ after ART [13]. The baseline prevalence of anemia reported from Hawassa and Jimma is lower than the present study. On the other hand, a study from North eastern Nigeria stated a prevalence rate of anemia in ART-naive patients was $57.7 \%$ and it was reduced to $24.3 \%$ in ART-experienced patients [15]. The reasons for the observed differences might be due to the difference in the study population, sample size, study design and variability in the definition of anemia.

The decrease in the prevalence of anemia after ART initiation is attributed to the positive effect of ART on the differentiation and survival of erythrocytes. HIV infection of marrow stromal cells, decrease in serum erythropoietin levels, auto-antibodies to erythropoietin, or marrow suppression by opportunistic infections, may contribute to the anemia commonly observed in HIVinfected patients. ART may ameliorate many of these effects in an indirect manner simply by decreasing the HIV viral burden [15].

In this study, the prevalence of anemia observed across sex groups was higher in men than in women before ART initiation (43.9\% vs $40.5 \%$ ), and lower after ART initiation (9.3\% vs. $12.8 \%)$. In agreement with this finding, a report from Benin city, Nigeria showed that among ART naive HIV patients, men had higher prevalence of anemia than their women counterparts $(76.42 \%$ vs $63.43 \%)$, and lower in those patients on ART $(44.19 \%$ vs $55.73 \%$ ) [16]. The findings in this study differ from the findings of a study in Hawassa, Ethiopia [14] and Addis Ababa, Ethiopia [17]. Female gender has been reported as a risk factor for anemia among HIV patients [8]. In the present study, the same finding was obtained among HIV patients who were receiving ART. Although statistically insignificant, the prevalence of anemia post ART initiation was dropped from 43.9 to $9.3 \%$ in men and from 40.5 to $12.8 \%$ in women.

We found that, the prevalence of anemia was increased with decreasing CD4 count both before and after ART initiation with a high prevalence among patients with CD4 count $<200$ cells $/ \mathrm{mm}^{3}$. In agreement with this finding, various studies reported that anemia was more prevalent among HIV patients with CD4 count $<200$ cells $/ \mathrm{mm}^{3}[3,4,11,18]$. In general, in the advanced stage of the disease, the blood cell counts were lower than the early stage of the diseases. This might be due to the increasing trend in the frequency of bone marrow abnormalities with progressive immunologic deterioration and advanced disease due to HIV $[19,20]$.

The types of anemia were also assessed in this study. Among the total number of anemic cases, normocytic normochromic anemia was present in 71 and $58.6 \%$ of the cases before and after ART initiation respectively. A study conducted in Gondar, Ethiopia reported that the prevalence of normocytic normochromic anemia in ART naive patients was $48.9 \%$, which reduced to $29.4 \%$ in those patients on ART [21]. This difference might be due to a difference in the definition of the types of anemia.

In the present study the relatively higher risk of developing microcytic hypochromic anemia was found in HIV positive patients before ART as compared to those on ART. Another cross sectional study in Ghana showed that, the likelihood of developing microcytic hypochromic anemia in ART-naive patients was five times more compared to those on ART [22]. This may reflect the overall nutritional deficiencies (malnutrition and malabsorption) associated with HIV patients.

This study also found that macrocytic normochromic anemia was present in $4.7 \%$ of anemic subjects at the baseline which was increased to $27.6 \%$ after ART initiation. This showed that the average MCV for patients on ART were significantly higher compared to their ART naive patients and the degree of macrocytosis is more to the group receiving zidovudine. In agreement with the current findings, studies conducted in Ghana [22] and Ethiopia [21] reported that macrocytic normochromic anemia was more common after ART than before ART initiation. This is probably due to the effect of ART particularly AZT which is responsible for the development of macrocytosis.

This study assesses the prevalence of anemia before and after initiation of ART. However, this study had limitations such as lack of age and sex matched healthy control group. Also the study does not address viral load and albumin levels because of lack of resources. In addition, this study did not include baseline data on BMI. Nevertheless, this study provides valuable information about the burden of anemia among HIV positive patients before and after ART.

\section{Conclusions}

There was a remarkable reduction in the prevalence of anemia after ART initiation. WHO clinical stages and $\mathrm{CD} 4+\mathrm{T}$ cell counts were associated with the prevalence of anemia before ART initiation. Normocytic normochromic anemia was the commonest type of anemia before and after ART initiation. Based on the present 
findings, a significant proportion of HIV patients remained anemic after 6 months of ART initiation suggesting the need for routine screening and proper treatment of anemia to mitigate its adverse effects.

\author{
Abbreviations \\ 3TC: Lamivudin; AIDS: Acquired immunodeficiency syndrome: \\ ART: Antiretroviral treatment; AZT/ZDV: Azidothymidine/Zidovudine; \\ BMI: Body mass index; CD4: Cluster of differentiation 4; EVF: Efavirenz; \\ Hgb: Hemoglobin; HIV: Human immunodeficiency virus; MCH: Mean cell \\ hemoglobin; MCHC: Mean cell hemoglobin concentration; MCV: Mean cell \\ volume; NVP: Nevirapine; RBC: Red blood cell; RDW: Red cell distribution \\ width; TDF: Tenofovir
}

\section{Acknowledgments}

The authors would like to extend their deepest appreciation to staff member of ART clinic of Black Lion Specialized Hospital for their cooperation, who providing the necessary information for this study. We also would like to thank all study participants for their cooperation. We are grateful to thank Addis Ababa University for sponsoring this research project.

\section{Funding}

This study was funded by Addis Ababa University. The funders had no role in study design, data collection and analysis, decision to publish, or preparation of the manuscript.

\section{Availability of data and materials}

The datasets used and/or analyzed during the current study are available from the corresponding author on reasonable request.

\section{Authors' contributions}

GGW: Develop proposal and data collection sheet, collected data, analyzed it and wrote the draft of the manuscript. DHW: Conceived the study, supervised the data collection and reviewed the draft of the manuscript. Both authors read and approved the final draft of the manuscript.

\section{Ethics approval and consent to participate}

The study was conducted after ethical letters obtained from departmental research committee (DRC) of the Department of Medical Physiology, Addis Ababa University, Ethiopia. Then permission was taken from hospital higher management and data was collected after obtaining written informed consent from the study subjects. To keep confidentiality codes were used and unauthorized person didn't have access to the data.

\section{Consent for publication}

Not applicable.

\section{Competing interests}

The authors declare that they have no competing interests.

\section{Publisher's Note}

Springer Nature remains neutral with regard to jurisdictional claims in published maps and institutional affiliations.

\section{Author details}

${ }^{1}$ Department of Medicine, College of Medicine and Health Sciences, Wolkite University, P.O. Box 07, Wolkite, Ethiopia. ${ }^{2}$ Department of Medical Physiology, School of Medicine, College of Health Sciences, Addis Ababa University, Addis Ababa, Ethiopia.

Received: 5 July 2017 Accepted: 23 February 2018

Published online: 15 March 2018

\section{References}

1. Erhabor O, Ejele OA, Nwauche CA, Buseri Fl. Some haematological parameters in human immunodeficiency virus (HIV) infected Africans: the Nigerian perspective. Niger J Med. 2005;14(1):33-8.

2. Kyeyune R, Saathoff E, Ezeamama AE, Loscher T, Fawzi W, Guwatudde D. Prevalence and correlates of cytopenias in HIV-infected adults initiating highly active antiretroviral therapy in Uganda. BMC Infect Dis. 2014;14:496.
3. Dikshit B, Wanchu A, Sachdeva RK, Sharma A, Das R. Profile of hematological abnormalities of Indian HIV infected individuals. BMC Blood Disord. 2009;9:5.

4. Alamdo AG, Fiseha T, Tesfay A, Deber MK, Tirfe ZM, Tilahun T. Anemia and its associated risk factors at the time of antiretroviral therapy initiation in public health facilities of Arba Minch town, Southern Ethiopia. Health. 2015; 7(12):1657-64

5. Belperio PS, Rhew DC. Prevalence and outcomes of anemia in individuals with human immunodeficiency virus: a systematic review of the literature. Am J Med. 2004;116(Suppl 7A):27S-43S.

6. Bain BJ. Pathogenesis and pathophysiology of anemia in HIV infection. Curr Opin Hematol. 1999:6(2):89-93.

7. Volberding $P$. The impact of anemia on quality of life in human immunodeficiency virus-infected patients. J Infect Dis. 2002;185:110-4.

8. Moyle G. Anemia in persons with HIV infection: prognostic marker and contributor to morbidity. AIDS Rev. 2002;4(1):13-20.

9. Moore RD, Forney D. Anemia in HIV-infected patients receiving highly active antiretroviral therapy. J Acquir Immune Defic Syndr. 2002;29:54-7.

10. Curkendall SM, Richardson JT, Emons MF, Fisher AE, Everhard F. Incidence of anaemia among HIV-infected patients treated with highly active antiretroviral therapy. HIV Med. 2007;8(8):483-90.

11. Assefa M, Abegaz WE, Shewamare A, Medhin G, Belay M. Prevalence and correlates of anemia among HIV infected patients on highly active antiretroviral therapy at Zewditu Memorial Hospital, Ethiopia. BMC Hematol. 2015;15:6.

12. WHO. Hemoglobin concentrations for the diagnosis of anemia and assessment of severity. Vitamin and mineral nutrition information system. Geneva: World Health Organization; 2011.

13. Gedefaw L, Yemane T, Sahlemariam Z, Yilma D. Anemia and risk factors in HAART naive and HAART experienced HIV positive persons in south West Ethiopia: a comparative study. PLoS One. 2013;8(8):e72202.

14. Daka D, Lelissa $D$, Amsalu A. Prevalence of anemia before and after the initiation of antiretroviral therapy at ART center of Hawassa University Referral Hospital, Hawassa, South Ethiopia. Sch J Med. 2013:3(1):1-6.

15. Denu BA, Kida IM, Hammagabdo A, Dayar A, Sahabi MA. Prevalence of anemia and immunological markers in HIV-infected patients on highly active antiretroviral therapy in Northeastern Nigeria. Infect Dis. 2013;6:25-33.

16. Omoregie R, Omokaro EU, Palmer O, Ogefere HO, Egbeobauwaye A, Adeghe JE, Osakue SI, Ihemeje V. Prevalence of anaemia among HIVinfected patients in Benin City, Nigeria. Tanzan J of Health Res. 2009; 11(1):1-4.

17. Adane A, Desta K, Bezabih A, Gashaye A, Kassa D. HIV-associated anemia before and after initiation of antiretroviral therapy at ART Centre of Minilik II Hospital, Addis Ababa, Ethiopia. Ethiop Med J. 2012;50(1):13-21.

18. Tesfaye Z, Enawgaw B. Prevalence of anemia before and after initiation of highly active antiretroviral therapy among HIV positive patients in Northwest Ethiopia: a retrospective study. BMC Res Notes. 2014;7(1):1-5.

19. Santiago-Rodríguez EJ, Mayor AM, Fernández-Santos DM, Hunter-Mellado RF. Profile of HIV-Infected Hispanics with Pancytopenia. Int J Environ Res Public Health. 2015;13(1):38-45.

20. Dhurve SA, Dhurve AS. Bone marrow abnormalities in HIV disease. Mediterr J Hematol Infect Dis. 2013;5(1):e2013033.

21. Enawgaw B, Alem M, Addis Z, Melku M. Determination of hematological and immunological parameters among HIV positive patients taking HAART and treatment naïve in the antiretroviral therapy clinic of Gondar University Hospital, Gondar, Northwest Ethiopia: a comparative cross-sectional study. BMC Hematol. 2014;14:8.

22. Owiredu WK, Quaye L, Amidu N, Addai-Mensah O. Prevalence of anemia and immunological markers among Ghanaian HAART-naive HIV-patients and those on HAART. Afri Health Sci. 2011:11(1):2-15. 